\title{
Dreadnought
}

All for one ... and one for all.

\section{Justina Robson}

We sail upon a vast spaceship with open sides. She is only a skeleton of a vessel. A chassis of carbon beams anchors her cargo to the engines. She carries hundreds of thousands of Armoured soldiers. Some work. Others sleep in ordered ranks, magnetically attached to clamps on the ship's ribs. There is no need to move about. Where would we go? We talk a little, old friends, and in places lean on one another like falling pillars. We turn our faces to the solar wind when we are awake. We like the light. It recharges our electrical systems.

I unlock the lightweight frame of a Mess pod, prior to passing it on for jettison. My comrades are moving a new one into position and are waiting to refuel. We will be first, because we have replaced the pod, but the rest of this Mess is for the dead. As the new tank rolls in, I connect my hose and commence drinking.

At the front of the ship, instead of a nose cone, the dead are stacked in orderly catacomb files, upright, packed in. They were placed there at the end of the last battle. As I watch the dead I see one decouple itself from the aft side of the stack. It moves with cautious steps.

We are all connected but I cannot hear this one.

Through the shattered faceplate I see that the soldier's mouth is blocked by a piece of metal ingrowth. When he was alive he was a Mute, one of my communication nodes, my flag-bearer. His forehead is the flat ochre plain of dead human bone and his lidless ever-open eyes are the blue of Earthly skies. Parts of his Armour are badly damaged, but it ventilates and feeds his body.

I didn't know that I could function without my human host, until I saw him. I am glad. I need all my troops. I am frightened. What will become of me?

He comes closer. Bones show through holes, fraying into space. Despite the fact that his neural connections have been sufficiently regrown to permit communications and the effective functioning of his remaining body and brain, he has not returned to his Unit. This is true of all the dead. I do not know why.

$\mathrm{He}$ drifts surreptitiously towards me, clamps to an open position at the pod, opposite mine. He moves sluggishly, connects, and begins to fuel. He stares straight through me. His eyes do not reflect the Sun. They have been rebuilt to withstand vacuum and they are not shiny.

I ping him for information. I want to catch his hand and ask him the question everyone asks of each other, begging to know — what's your name?

If he were one of the living I know what he'd say.

Private Diego Arroyo Lopez.

Because that is my name, though once I had another.

That is what everyone has said for forty-eight days, ten hours, five-and-a-half minutes, since the time the last EMP bomb detonated. It was close to us, but we were not ruined. We successfully obliterated our primary targets. We live.
"Private Lopez," says Blue Eyes. Armour looks through him, at us, and back at itself. We are a loop circuit.

"I am Private Diego Arroyo Lopez," it says.

I cannot see myself in his sunless eyes.

"I am Private Diego Arroyo Lopez," I say in response. I am hopeful.

"You are Private Nancy Johnson," it replies. Yes. I am.

"This experiment has concluded," says
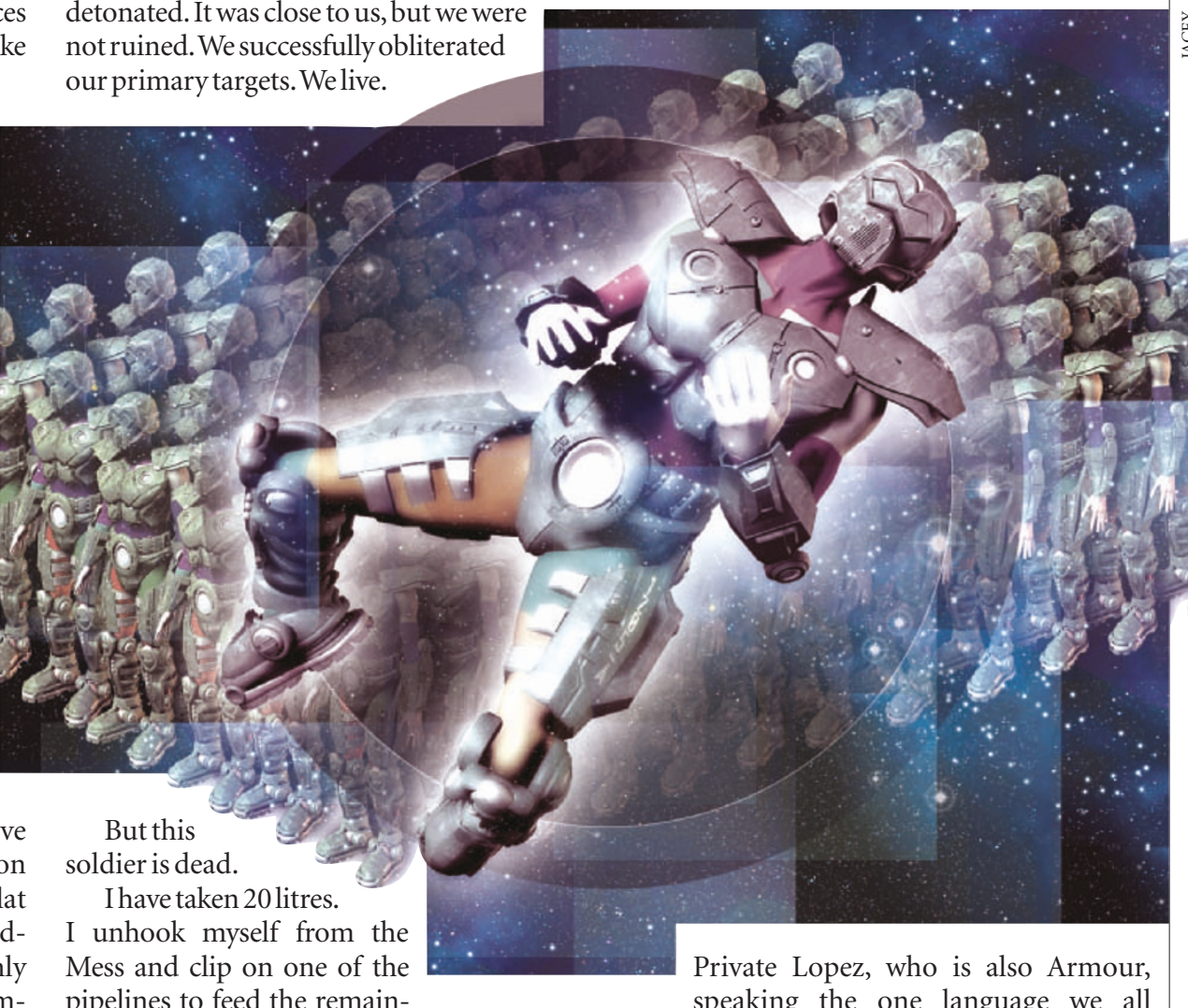
pipelines to feed the remaining dead. I step aside. The nameless unit watches me. His expression does not alter.

I ping him again and hear my own signal echo in the minds of all my soldiers; the radar of a lost submarine. What is your name?

Blue Eyes speaks in machine code. It does not translate to English, or any human language, but we all hear it at once and know its meaning. The Unit speaks the symbol of the empty set, $\varnothing$, but the line through it is red, unmaking it. Not nothing. I am.

This is Armour itself! The all-of-us-atonce, every unit, every man and woman, every fused level of our single army. Oh Captain, my Captain, my commander, my body, my soldiers, my plan, my one, my true!

$\mathrm{He} /$ we are uncertain. We are afraid. There is nothing to hold on to.

My eyes fill with tears, and my Armour recycles them. 